\title{
Estimating Selenium Status of Merino Ewes and Neonates Using a Randox Ransel Gshpx Kit
}

\author{
Shimin Liü ${ }^{1 *}$, Jason Lei ${ }^{1}$, Serina Hancock ${ }^{2}$, Victoria Scanlan², Gerard Smith ${ }^{3}$ and Andrew Thompson ${ }^{2}$ \\ ${ }^{1}$ Institute of Agriculture, The University of Western Australia, Australia \\ ${ }^{2}$ School of Veterinary and Life Sciences, Murdoch University, Australia \\ ${ }^{3}$ Department of Primary Industries and Regional Development Western Australia, Australia
}

Submission: July 19, 2018; Published: August 01, 2018

*Corresponding author: Shimin Liu, Institute of Agriculture, The University of Western Australia, Crawley, WA 6009, Australia, Tel: +61864886711; Email: shimin.liu@uwa.edu.au

\begin{abstract}
Blood glutathione peroxidase activity (GSHpx) can be used to indicate blood selenium (Se) concentration in ruminants, however GSHpx values for a given Se concentration vary among laboratories and assay kits and are specifically linked to the assay method. Here we measured GSHpx using a RANDOX Ransel kit, and blood Se using a chemical method in ewes and their neonates, and generated linear regression relationships between GSHpx and Se. The GSHpx values for deficient, marginal and adequate Se status $(0.05,0.075$ and $0.1 \mathrm{mg} / \mathrm{L}$ blood $)$ in adult Merino ewes are reported. Importantly, the relationship differed between adults and neonates.
\end{abstract}

Keywords: Selenium; RANDOX Ransel kit; Neonate, Sheep; Glutathione peroxidase; Quantitative; Literature; Constituents; Animal Ethics; Merino ewes; Linear regression; Erythrocyte; Livestock

\section{Introduction}

Selenium (Se) status in animals is usually established from analysis of Se in whole blood. The cost of the chemical analysis is high. Glutathione peroxidase (GSHpx) contains Se as a co-factor, its activity is closely related to Se concentration in blood and therefore, it is used to indicate Se status [1-3]. Various commercial kits are available for determining blood GSHpx activity. Variations in the constituents and analytical procedures amongst kits may result in variations in measured GSHpx activity on the same sample. This means GSHpx activity at a given Se concentration will vary depending on which assay kit used. This has not been examined in the published literature. This study established the quantitative relationship between blood Se concentration and GSHpx using a RANDOX Ransel kit RS505 (Randox Laboratories, Antrim, UK) and defined the threshold values for GSHpx activity for deficient, marginal, adequate Se status of Merino ewes and their neonates.

Animal management and experimental procedures were approved by the Animal Ethics Committees of the University of Western Australia and Murdoch University. The experiment was carried out under grazing conditions. On day 113 of pregnancy, 120 Merino ewes were divided into two groups of 60. One group received vitamin $\mathrm{E}+\mathrm{Se}$ (Vit $\mathrm{E}+\mathrm{Se}$ ) supplementation: $4 \mathrm{~g}$ dl- $\alpha$-te copherol acetate (Advanced Liquid E, WA) was orally adminis trated and $1.2 \mathrm{~mL}$ of Bayer Selovin $(60 \mathrm{mg}$ Se as barium selenate. Bayer Animal Health, NZ) was subcutaneously injected behind the ear. On days 124 and 140 of pregnancy a second and third dose of vitamin E was orally administrated. The control group received no supplements. Management of animals and sampling procedures have been described elsewhere [4]. Blood samples were collected from ewes on the day of lambing and from neonates prior to suckling for, and blood cells were used for analysis of GSHpx activity next day and Se.

Glutathione peroxidase (GSHpx) activity in erythrocytes was determined using Ransel 505 kit. Haemoglobin (Hb) was measured using RANDOX HG1539 kit. GSHpx activity was expressed as IU/gHb. Selenium concentrations in samples of blood cells were determined using the method of Gelman [5]. The relationship between Se concentration and GSHpx activity respectively for ewes and their neonates were analysed using GenStat (Version 16, VSN International). Selenium concentration in erythrocyte $(\mathrm{mg} / \mathrm{L})$ of ewes at lambing was 1.96 times higher in the Vit $\mathrm{E}+$ Se group compared with the Control groups $(\mathrm{P}<0.001)$, and the Se concentration in their neonates was 1.28 times higher than the concentration for the Control groups $(\mathrm{P}<0.001)$ (Table 1). 
Table 1: Selenium concentration ( $\mathrm{mg} / \mathrm{L}$ erythrocyte) and glutathione peroxidase activity $(\mathrm{IU} / \mathrm{g} \mathrm{Hb})$ of ewes and neonates.

\begin{tabular}{|c|c|c|c|c|c|c|c|c|}
\hline & \multicolumn{2}{|c|}{ Control (n=53) } & \multicolumn{2}{c|}{$\begin{array}{c}\text { Vit } \\
\text { E=Se(n=29) }\end{array}$} & \multicolumn{2}{c|}{ SED } & \multicolumn{2}{c|}{ P Values } \\
\hline & Se & GSHpx & Se & GSHpx & Se & GSHpx & Se & GSHpx \\
\hline Ewes & 0.077 & 105 & 0.228 & 363 & 0.019 & 29.2 & 0.001 & 0.001 \\
\hline Neonates & 0.06 & 102 & 0.137 & 276 & 0.01 & 22.8 & 0.001 & 0.001 \\
\hline
\end{tabular}

There was a significant linear relationship between Se concentration (mg/L erythrocyte) and GSHpx activity (U/g Hb) for both ewes and neonates (Figure 1). However, the regression relationship differed between ewes and neonates $(\mathrm{P}<0.001)$. Therefore, separate regression equations were generated for each age class. There was a significant linear relationship between the maternal and neonate Se concentrations. The coefficient of the regression equation was 0.42 , indicating that a unit change in maternal Se concentration resulted in a 0.42 unit change in the neonate.

To convert Se concentration in erythrocytes to Se concentration in whole blood (for comparison with other published studies), a factor of 1.3 was used as erythrocyte Se is $30 \%$ higher than whole blood Se concentration [6]. Thus, two new regression equations were derived:

Ewes: Se $(\mathrm{mg} / \mathrm{L}$ blood $)=0.0132+0.000445$ GSHpx $(\mathrm{U} / \mathrm{g} \mathrm{Hb})$ (1)

Neonates: Se $(\mathrm{mg} / \mathrm{L}$ blood $)=0.0179+0.0003 \mathrm{GSHpx}(\mathrm{U} / \mathrm{g}$ $\mathrm{Hb})(2)$

For ewes, GSHpx values of 83, 138 and 195 (U/gHb) corresponded to blood Se concentrations of 0.05, 0.075 and 0.1 Table 2: Estimated GSHpx activity $(\mathrm{U} / \mathrm{gHb})$ for the whole blood Se status thresholds for sheep and cattle.

\begin{tabular}{|c|c|c|c|c|c|c|c|}
\hline \multirow{3}{*}{ Animal species } & \multicolumn{3}{|c|}{ Whole blood Se status (mg/L) } & \multirow{3}{*}{$\begin{array}{l}\text { Se range in original data } \\
\text { (mg/L erythrocyte) }\end{array}$} & \multirow{3}{*}{$\mathbf{n}$} & \multirow{3}{*}{$\begin{array}{l}\text { GSHpx } \\
\text { Assay }\end{array}$} & \multirow{3}{*}{ Reference } \\
\hline & Deficiency & Marginal & Adequate & & & & \\
\hline & 0.05 & 0.075 & 0.1 & & & & \\
\hline & \multicolumn{3}{|c|}{ Estimated GSHpx (U/gHb) } & & & & \\
\hline Sheep, ewes & 83 & 138 & 195 & $0.02 \sim 0.40$ & 82 & Ransel 505 & This study \\
\hline \multirow[t]{3}{*}{ Neonates } & 107 & 190 & 275 & $0.03 \sim 0.29$ & 82 & & \\
\hline & 43 & 89 & 133 & $0.03 \sim 0.22$ & 43 & Laboratory & 7 \\
\hline & $<30$ & $<50$ & Up to 500 & & & Laboratory & 8 \\
\hline \multirow[t]{3}{*}{ Cattle } & 24 & 47 & 70 & $0.03 \sim 0.15$ & 191 & Laboratory & 7 \\
\hline & 122 & 204 & 285 & $0.01 \sim 0.14$ & 48 & Laboratory & 1 \\
\hline & $<20$ & $<40$ & Up to 300 & & & Laboratory & 8 \\
\hline
\end{tabular}

We also showed that the relationship between Se concentration and GSHpx activity differed between ewes and neonates. Thus, the GSHpx threshold values derived in adult animals cannot be applied directly to assess the Se status in neonates. This means age specific thresholds are required for GSHpx activity even within one kit or method.

The GSHpx data from Anderson et al. [7] was expressed

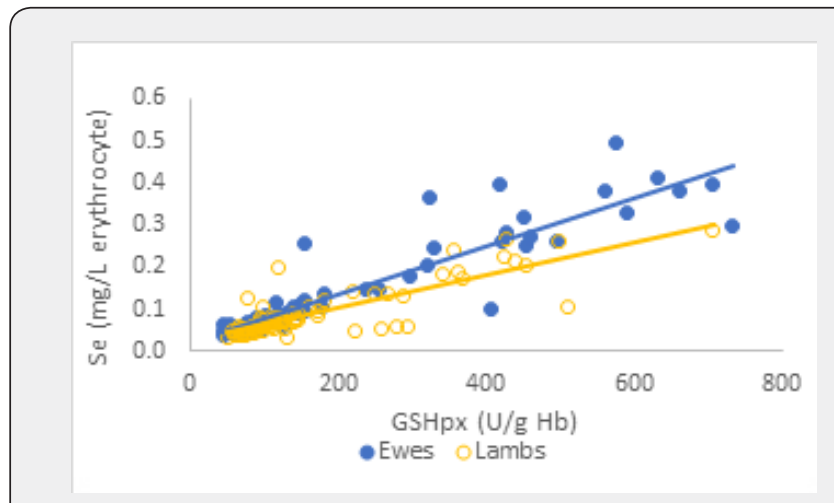

Figure 1: Relationships between GSHpx and Se concentration in ewes $(n=82)$ and their neonates $(n=82)$.

Ewes: $\mathrm{Se}(\mathrm{mg} / \mathrm{L}$ erythrocyte $)=0.0171(\mathrm{SE} 0.006)+0.000579$ (SE 0.00002) GSHpx (U/g Hb), R2 = 0.85, P<0.001

Neonates: $\mathrm{Se}(\mathrm{mg} / \mathrm{L}$ erythrocyte $)=0.0233(\mathrm{SE} 0.006)+0.000393$ (SE 0.00003) GSHpx (U/g Hb), R2 = 0.72, $\mathrm{P}<0.001$.

$\mathrm{mg} / \mathrm{L}$, for neonates the corresponding GSHpx values were 107, 190 and $275 \mathrm{U} / \mathrm{gHb}$ (from equations (1) and (2) (Table 2). These blood Se concentrations are recognized as the thresholds for deficient, marginal and adequate status in mature ruminants [1]. We established the GSHpx values that corresponded to thresholds of Se status (deficient, marginal and adequate) using a RANDOX Ransel GSHpx kit. When these GSHpx activities were compared with other reports (Table 2) $[1,7,8]$ available in the literature, there were substantial differences between the results. Therefore, when blood GSHpx value is used to indicate the Se status of sheep, the method or kit should be clearly described, and caution is required in comparing GSHpx across

as $\mathrm{U} / \mathrm{mL}$ erythrocyte in the linear regression equation. The calcualted GSHpx values in erythrocyte were converted to GSHpx per gHb using the $\mathrm{Hb}$ concentration of $0.316 \mathrm{~g} / \mathrm{L}$ erythrocyte from this experiment. The authors acknowledge the financial support of Meat and Livestock Australia, chemical analyses by Maicam Nguyen, Department of Primary Industries and Regional Development Western Australia and field assistance by Amy Lockwood and Samantha Sterndale, Murdoch University. 


\section{References}

1. Counotte GHM, Hartmans J (1989) Relation between selenium content and glutathion-peroxidase activity in blood of cattle. Vet Quart 11: 155160

2. Pleban PA, Munyani A, Beachum J (1982) Determination of selenium concentration and glutathione peroxidase activity in plasma and erythrocytes. Clin Chem 28(2): 311-316.

3. Ullrey DE (1987) Biochemical and physiological indicators of selenium status in Animals. J Anim Sci 65(6): 1712-1726.

4. Lockwood A, Currie A, Hancock S, Broomefield S, Liu S, et al. (2016) Supplementation of Merino ewes with cholecalciferol in late pregnancy improves the Vitamin D status of ewes and lambs at birth but is not correlated with an improvement in immune function in lambs. Anim Prod Sci 56: 757-766.

5. Gelman AL (2010) Some studies with an Agilent VGA-76 hydride generator for selenium determination. Agilent Technologies, Inc., USA p. 1-6.

6. Barceloux D (1999) Selenium. J Toxicol Clin Toxic 37: 145-172.

7. Anderson PH, Berrett S, Patterson DSP (1978) Glutathione peroxidase activity in erythrocytes and muscle of cattle and sheep and its relationship to selenium. J Comp Path 88: 181-189.

8. Paynter DI (1996) Diagnosis of mineral deficiencies. In: Masters DG, White CL, editors. Detection and Treatment of Mineral Nutrition Problems in Grazing Sheep. Aust Int Agri Res, Canberra p. 45-56.

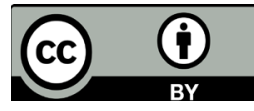

This work is licensed under Creative Commons Attribution 4.0 License DOI: 10.19080/JDVS.2018.07.555704 